\title{
VULNERABILITY OF ELDERLY IN THEIR HOME ENVIRONMENT AT HIGH DENSELY SETTLEMENT
}

\author{
Diananta Pramitasari*1, Ahmad Sarwadi ${ }^{2}$ \\ 1,2 Universitas Gadjah Mada \\ e-mail: *1dpramitasari@ugm.ac.id, 2a_sarwadi@yahoo.com
}

\begin{abstract}
This study basically aims to examine the vulnerability of the elderly when they are using the space in their home within a high densely settlement. Due to the high density of the urban settlement, the condition of the elderly living unit that located in the middle of settlement area is questioned. Under the condition of lack of space, actually two questions are appeared. First question is "how do the elderly residents use the space for their daily life?". Moreover, the second question is about "is the room as well the home environment good enough for supporting the elderly daily activities and maintaining their health?" These questions are actually directing to necessary of examining the vulnerability the elderly in their own home. This study was carried out through conducting field observation and doing the individual interview in two neighborhoods located at the city center of Yogyakarta City. By interviewing the elderly residents this study identified the room or spaces that most frequently used the senior residents during their lives inside their own home. The identification then proceeds in to the assessment of the space condition especially related to the natural lighting and ventilation. This study found that in urban settlement with high density and aging population, there was subtle vulnerability existed in the spaces within the elderly's home that most frequently used. This vulnerability was sourced at the conditions of natural lighting and fresh air ventilation that performed by the home environment properties. These physical aspects of the space considered significant since the resident houses were in very limited urban spaces. Although the vulnerability is subtle or slight, this condition indicates that the elderly residents' health is really threatened.
\end{abstract}

Keywords: Elderly; Home Environment; High Densely Settlement; Use of Space; Vulnerability.

\footnotetext{
${ }^{1}$ Universitas Gadjah Mada

${ }^{2}$ Universitas Gadjah Mada
} 


\section{INTRODUCTION}

As a city grows along the continuum of time, its population is becoming older. Yogyakarta City has some areas located in the city center that grow to become high densely urban settlement and in the same time has its population that can be categorized as becoming aging in place. William (2004) described the term of aging in place as a condition where the senior resident lives in his own dwelling safely, independently and comfortably, in any case of age, income and ability level. Referring this definition, senior residents in the urban settlements of Yogyakarta City are actually facing and becoming aging in place, since the number of institutional cares for serving the dwelling facilities for the elderly is still limited. Especially in the high densely settlement of the city center, the senior citizens remain staying at their own homes. Elderly keep staying in their own old homes as they have spent years in the living environment so that their willingness to move is so little (Temelova, 2012). Due to the decline of their physical ability, the elderly spends their time dominantly within their home environment. The home environment, therefore, has a significant impact on elderly's ability to age in place (Burton, E., Michell, L., Stride, 2011). In their home environment, with the assistance of their caretaker, the elderly may adjust their existing environment so that they may perform the daily activities independently (Galof \& Gricar, 2017). Under the condition of lack of space due to the limited dwelling space in the urban settlement, how the elderly residents use the space for their daily life is becoming the inquisition. Moreover, concerning the decline of some physical capability of the senior residents, how the home environment may anticipate the elderly's handicap is necessary to be identified. Various studies dealing with the quality of life of the elderly residents in the urban settlement have been conducted. The study by (Elo, 2010) exposed that the physical environment that supports the wellbeing of the elderly is an environment that enables elderly to conduct activity safely and provides them a pleasant physical environment.While, in the study of (Iwarsson, 2007) it was confirmed that in promoting healthy society, it is necessary to create home environment that support the healthy aging. One consideration of Szanton's study (2014) is that the elderly are not only living independently in their own homes but also actually being able to choose how to spend their days.Impacts associated with the high densely settlement are related to various features, which is in negative or positive qualities. Elisabeth Schröder-Butterfilland Ruli Mariyanti' study (2006) on old-age vulnerability stated that the important implication of their research wasidentification of prevention and policy needed to assess individuals or subgroups who were several steps away from a problem, and the requirement to understand both the sources and the consequences of vulnerability. This research concerns on physical sources of vulnerability. Poor quality of home environment such as lack of natural ventilation and daylight need to be investigated because of the importance natural ventilation and daylight for healthcare requirement. Based on the background stated above, it is important for the study to examine the vulnerability of the elderly when they are using the space in their home.

\section{RESEARCH METHODS}

This study has a deductive characteristic using some theories as bases to conduct field observation for exploring the real field condition. The location of study was selected to achieve the study aim (purposive location). This study' s location is a neighborhood in a high densely urban area with high population of the aging people. The detail explanation on the research method is written below.

This study took two neighborhoods located in Yogyakarta city center as study areas. According to the area administrative taxonomy in Yogyakarta City, the selected neighborhoods are N

the two of 13 neighborhood areas called RW (Rukun Warga). The study areas are RW7 and RW12 
neighborhoods. These neighborhoods were chosen based on consideration that they are areas with high population density. The RW7 neighborhood has a density of 41,542 person per sq.km., while RW12 neighborhood has a density of 16,069 people per sq.km. The other consideration is related to the elderly population of these two neighborhoods that is over than $7 \%$. This means that the population can be stated as old-structured population. The RW7 neighborhood's elderly population is reaching $12.1 \%$ of the total population of the neighborhood, while the RW12 neighborhood's is about 15.04\% (Central Bureau of Statistic, 2014). Based on the considerations above, the two neighborhoods were taken. Moreover, from the existing block plan of the neighborhood, it is shown that these two high densely old neighborhoods have different mass grain of their living units. RW7 has rather small masses of the houses in the entire area, while RW12 has relatively bigger masses of the housing units spread out at the area. This different characteristic of the micro scale urban grain of the neighborhood was also evidenced through preliminary survey as well the detailed survey. In RW7, the residents especially those who live inside the block are living in small-size houses. Their small houses are very close to each other and side-by-side are facing narrow alleys. Meanwhile, in RW12 relatively larger houses are present at the parts of the neighborhood especially that are close to the big streets.
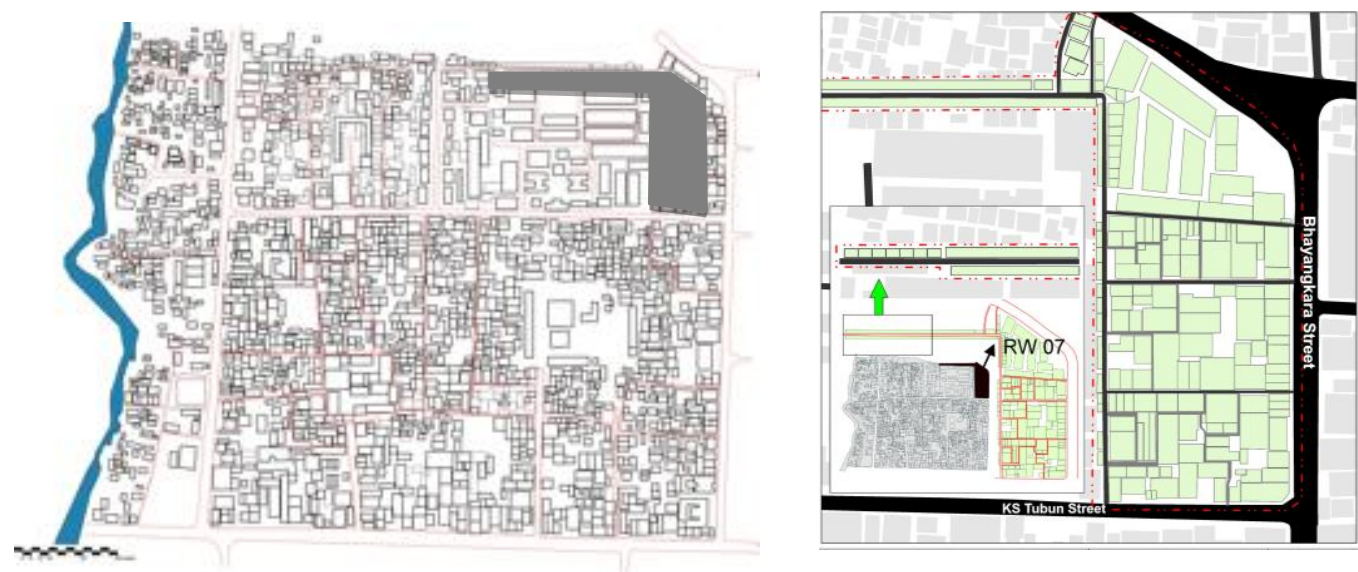

Figure 1. (left) Block plan of Ngampilan Urban Village with RW7 neighborhood area at the northeast edge; (right) Base map of RW7 neighborhood area Source: Kartamantul \& google map modified by confirmations survey 2015.
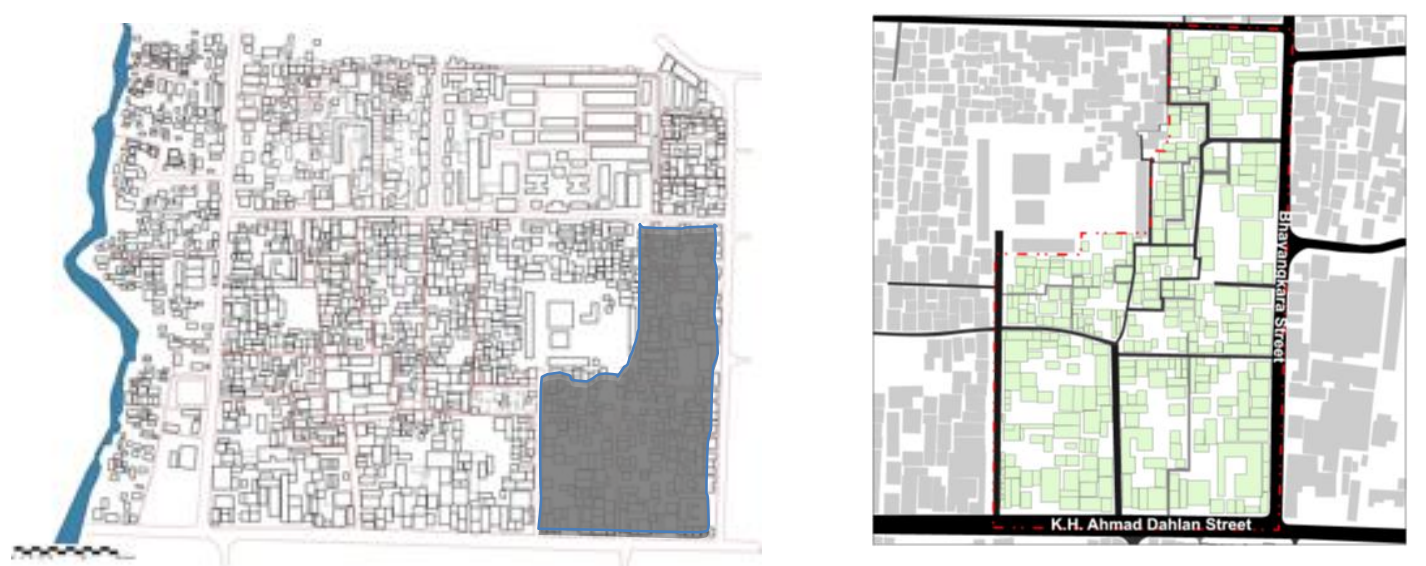

Figure 2. (left) Block plan of Ngampilan Urban Village with RW12 neighborhood area at the southeast edge; (right) Base map of RW12 neighborhood area Source: Kartamantul \& google map modified by confirmations survey 2015. 
Various methods of collecting the data can be conducted in understanding the daily activities of the elderly residents as well the use of space, such as interview methods (Korosec Serfaty, 1984); (Marcus, 1995); (Hauge \& Kristin, 2008); (Dianita Pramitasari \& Et, 2014),completing questionnaires (Parker 1999); (Diananta Pramitasari \& TYW, n.d.), and even filling out the activities check list. Among these methods, even though the decision of choosing the data collection method depends on the aim and purpose of study, the method of interview is considered as best method in obtaining the data from the research subjects. The subjects of this study are elderly residents of the RW7 and RW12 neighborhoods. They were asked about their daily activities inside their home environment. In RW7 neighborhood elderly who formally registered as residents of the neighborhood are 88 persons, while in RW12 neighborhood 157 persons. Based on this data, the surveyor then tried to find out the opportunities to visit and have interview with the elderly residents. Through facing some technical obstacles such as being disabled to meet the respondent due to uncompromised meeting time, being refused by the respondents without clear reasons, and getting communication difficulties due to the decline of the communication abilities of the elderly, finally significant numbers of elderly were successfully interviewed. In RW7, among 88 elderly residents, finally 42 persons ( $15 \mathrm{~m}$ and $27 \mathrm{f}$; average of age is 71.09 years old) have completed the interview session. While in RW12, 51 respondents $(17 \mathrm{~m}$ and $34 \mathrm{f}$; average of age is 69.412 years old) have been interviewed. They were asked some questions, mainly about the use of space within their home environment. Observations on respondents' houses condition were also conducted to obtain the physical data on their home environments. Figure 3 below shows the locations of the respondents' houses of each neighborhood.

\section{Environmental assessment during observation}

In order to examine the vulnerability of the elderly in their own homes, one possible approach is examining the physical quality of the houses. In this point, the concern is on how their home environment serve and protect their inhabitants so that they can live comfortably and healthy inside. The limited of space as a characteristic of urban settlement results in the problem of natural daylight and natural ventilation of the living units. The preliminary survey in the study area also resumed these situations, therefore the focus of the observation then was put on the three aspects: natural daylight and natural ventilation. There are some references help to set specific technical standards for various physical components of house in the mid of urban settlements. Dealing with an aspect of natural lighting for elderly house, one guidebook especially for elderly housing (Isaac \& Et.al., 1975) proposed that the area of natural light (window area) should be at least $15 \%$ of the total amount of floor area of the room to be lighted. While, according to design guideline from Ministry of Health (Keman, 2005) the lighting, both daylight of artificial light, for the indoor space should lights covering the whole room that should be lighted with the light intensity at least 60 lux and does not impact on eye dazzle. Other reference, Architect's Data (Neufert, 1990), suggested that the room where the elderly live should have a lighting system that permit a balance lighting throughout the room area while in the same time avoiding glares and blind spots. In this guidance there is no clear distinguish between lighting of natural daylight and artificial one. Considering some references on lighting aspect for the room dwelled by the elderly, this study then tried to set criteria for a lighting contextual for the study case. During the field observation, while interviewing the respondents, the surveyor conducted assessment to the room lighting especially on daylight condition. The assessment constitutes two types of quality: enough and poor. The "enough" quality refer to the room with the window area has a size at least $15 \%$ of the intended room's floor area. While the "poor" quality refers to the situation when the daylight in the room is less than what it situated in the enough criteria. 

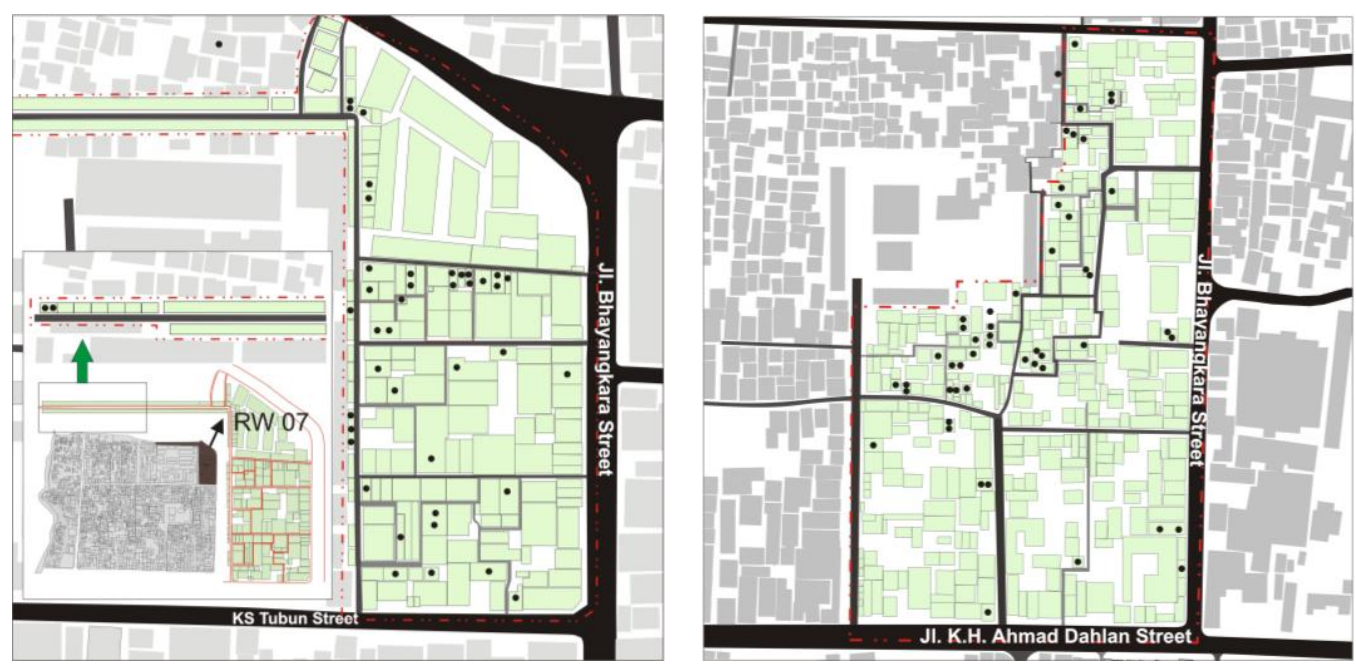

Figure 3. Mapping of Respondents' house (RW 7 left and RW12 right) Source: Kartamantul \& google map modified by field survey 2015.

In the aspect of air ventilation for technical requirements in the elderly house design, there are also several references deal on suggestions. Manual book for elderly housing (Feddersen \& Ludtke, 2009) describes that the area of natural ventilation or fresh air in dwelling units should amount to at least 5\% of the floor area of the room that is to be ventilated. Meanwhile, a design guideline from Ministry of Health ${ }^{8}$ explains that the area size for air ventilation permanent window or hole at the wall should be at least $10 \%$ of the floor area of the room. Considering some notes on these technical suggestions form the references, this study put the criteria for good ventilation for the elderly home that result in two types, enough and poor. Enough quality of ventilation is put on the room that has a permanent window for air ventilation with the size at least $10 \%$ of its total floor area. While poor quality refers to condition of ventilation that is less than condition situated in the enough criteria

\section{RESULT AND DISCUSSION}

\section{Respondents' Home Environment}

\section{Physical Condition of Home and the Environment}

As mentioned above, the study areas are located in the corner or hook of the urban village area or block. It implies in the closeness of these study areas to the street that connecting the area to the very center of the city of Yogyakarta. Moreover, the edge of the study area consists of the street approaching the city center and the local street that being covered by asphalt materials and frequently being passed over by various vehicles. Across the study areas, there are some alleys and small roads with various levels of accessibility. Some of these alleys are vehicle prohibited.

From the interview with the respondents from two neighborhoods, the data shows that the profile of respondents' houses is significantly different between the two study areas, based on the area size of houses. In RW7, the house size is dominantly in the smallest size type (less than 25 sq. meter, about 38\%). In contrast, the house size dominant in RW12 is the largest size type (larger than 100 sq. meters, reaching 43\%). Interestingly, in RW7 the minority of house size type is the second largest size (76-100 sq. meters, $5 \%)$ and in RW12 the smallest size type $(<25$ sq. meters, $10 \%)$. 

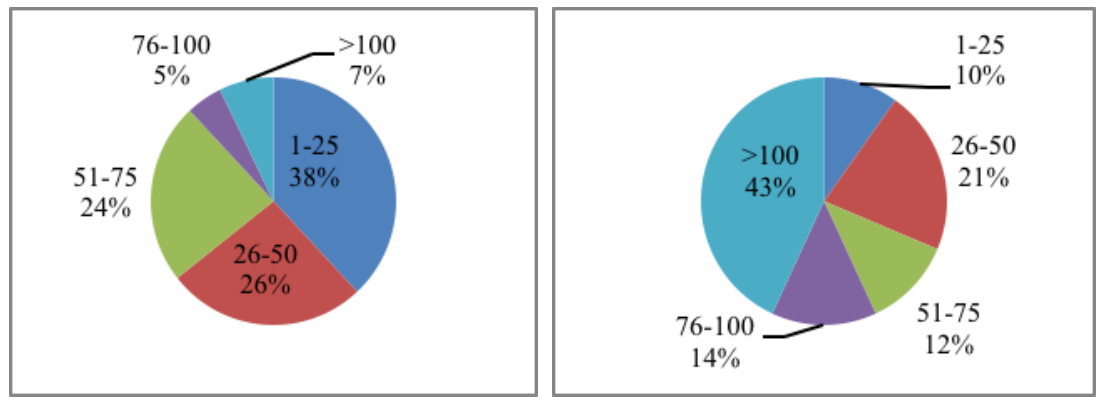

Figure 4. Respondents' house size (left: RW7, right: RW12)

\section{Use of Space in the Respondents' Home}

The data collected from the interview is basically about the use of space within the respondents' houses including the information on space or room where the elderly spend much time or use most frequently during the day.
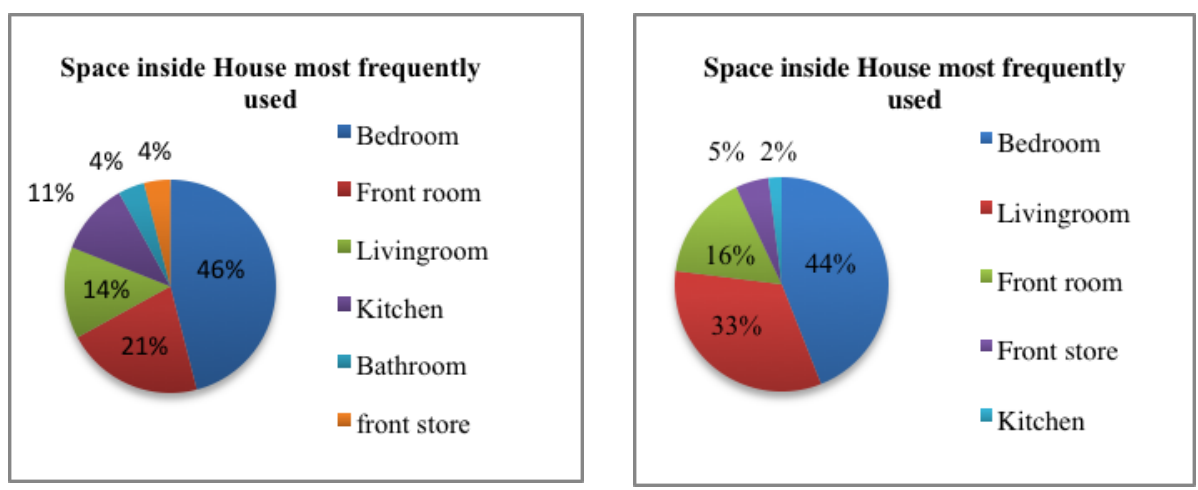

Figure 5. Space inside house that most frequently used by the respondents (left: RW7, right: RW12)

Giving attention to the result of the interview described in Figure 5, it is identified that space that is mostly used or frequently occupied by the elderly respondents is bedroom. In both study areas, bedroom is the most frequently used space. This can be understood especially related to the physical condition of the elderly that commonly tends to suffer declination. Although some certain elderly still maintain their active mobility, dominantly the senior residents prefer to stay longer in their most familiar space. That is bedroom.

\section{Physical Condition of Most Frequently-Used Space}

After identifying spaces that are mostly used or occupied by the elderly residents during their days in their home, an inquiry regarding the conditions of these spaces came up. Since the elderly inhabitants tends to stay longer in certain spaces inside their home due to their physical motoric decrease, it is important to confirm the condition of these such spaces that actually should support the elderly's activities as well sustaining their health. As described above concerning the assessment to the natural lighting and ventilation of the room within the elderly home environment, the result show that poor quality are still found among the respondents' houses. 

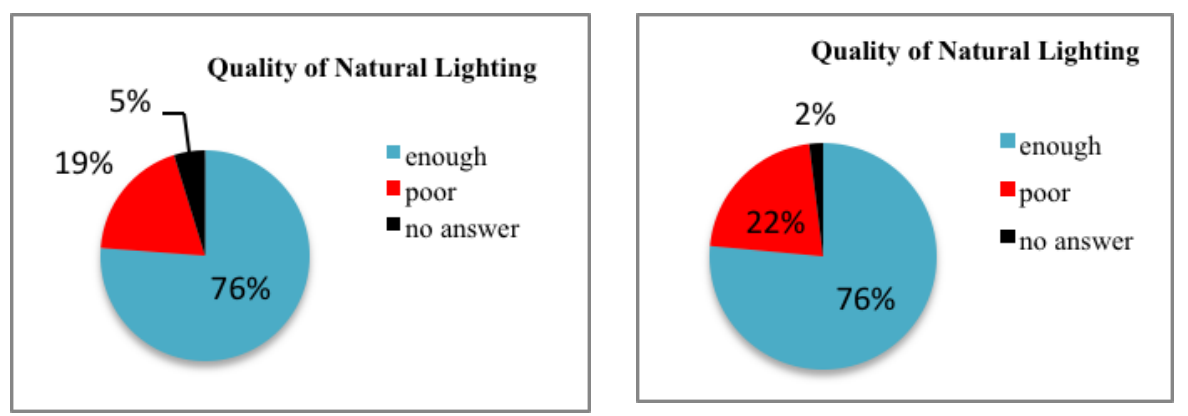

Figure 6. The Condition of Natural Lighting of the Most Frequently Used Space within Respondents' House (left: RW7, right RW12)

The left graphic in Figure 6 shows the natural lighting condition in RW7. Nineteen percent of the frequently used space within the elderly home is in poor condition. Although it can be seen that about $76 \%$ spaces is considered having enough natural lighting, still the appearance of poor condition in some few houses should carefully concerned. The relatively similar condition is also found in RW12. The assessment data shows 22\% spaces are in poor condition. Moreover, percentage is slightly higher than RW7's situation. The graphic also show the symbol of "no answer". This means that the surveyor could not give assessment to natural lighting condition of the room due to the refuse from the respondents for the surveyor to enter the room or even houses. Figure 7 below shows the mapping of the houses containing frequently used spaces that were assessed by natural lighting condition. The map in the above is RW7 that is visualized in the same scale with RW12 map in the below. Through the same scale, the size of house mass building can be compared to support the further analysis on the related data.
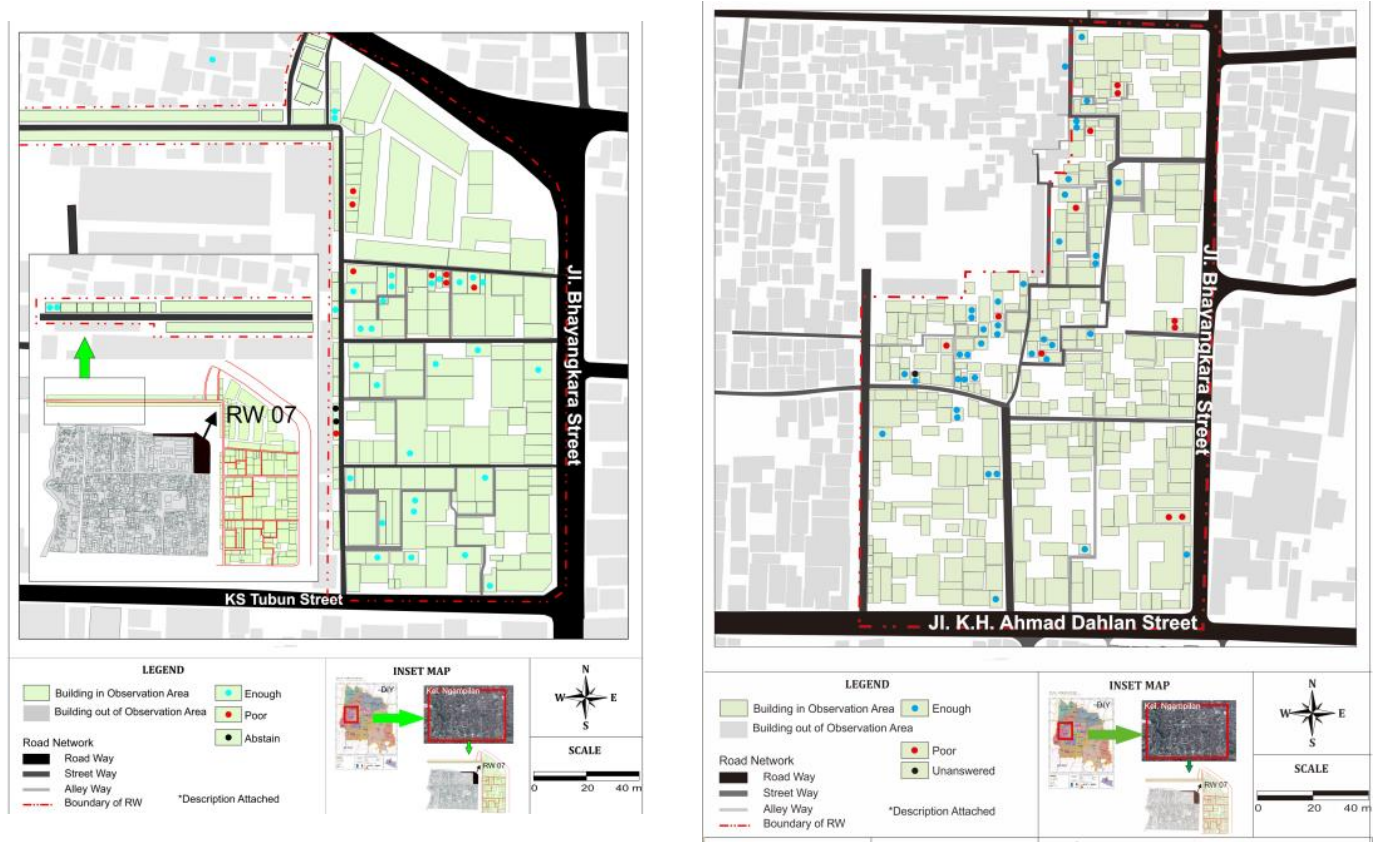

Figure 7. The mapping of houses with quality of natural lighting (left: RW7, right: RW12) 

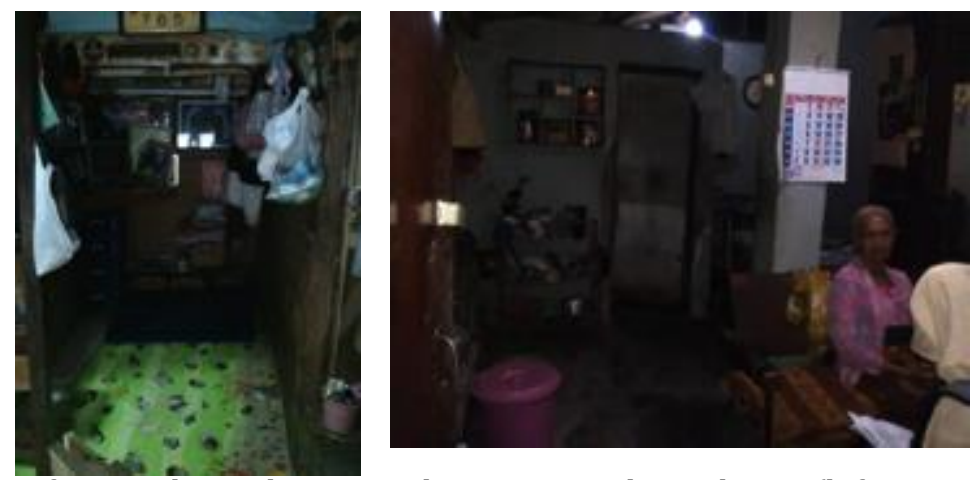

Figure 8. Most frequently used space with poor natural ventilation (left: in RW7) and natural lighting (right: in RW12)

Figure 8 above shows two photos of the interior of the most frequently used space of the respondent (RW7 in the left side, RW12 in the right side) that has poor quality in ventilation (left) and natural lighting (right). In the aspect of natural air ventilation, the assessment data show the result as described in the figure 9 below. The left graphic show the fresh air ventilation condition in RW7. Fourteen percent of the frequently used space within the elderly home is in poor condition. Although it can be seen that about $83 \%$ spaces is considered having enough ventilation or window for passing the fresh air from outside to inside the room, still the appearance of poor condition in some few houses should carefully concerned. The relatively similar condition is also found in RW12. The assessment data shows $18 \%$ spaces are in poor condition. Moreover, percentage is slightly higher than RW7's situation. Figure 10 below shows the mapping of the houses containing frequently used spaces that were assessed by air ventilation condition. In the graphic show the symbol of "no answer". This means that the surveyor could not give assessment to the ventilation condition of the room. The reason of this situation is about the difficulty to be permitted by the respondent to enter the room. The map in the above is RW7 that is visualized in the same scale with RW12 map in the below. Through the same scale, the size of house mass building can be compared to support the further analysis on the related data.
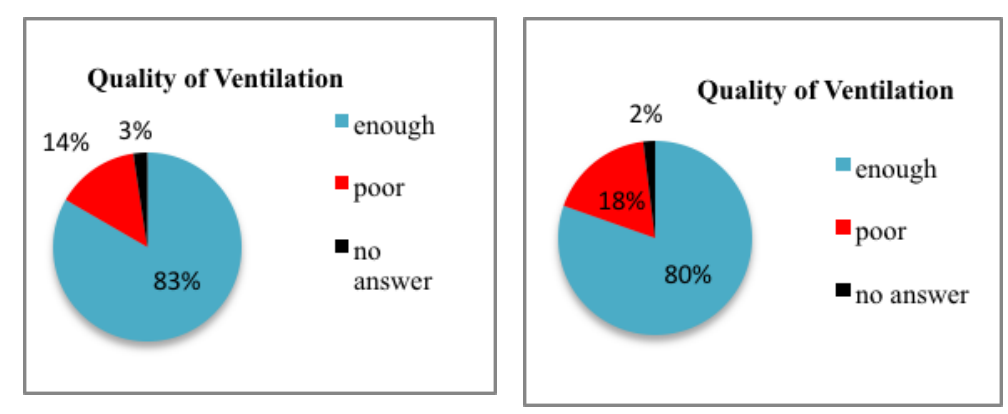

Figure 9. The Condition of Ventilation of the Most Frequently Used Space within Respondents' House (left: RW7, right RW12)

In the beginning, the intention to put the two neighborhood as study areas is to evaluate whether the size of house give a considerable association to the quality of indoor space especially natural lighting and ventilation. Then, through comparing the data resulted from the field observation, quick assessment and personal interview, the quality of the two aspects of both neighborhood are relatively similar. In this study, as described above, the first identification is that 
the room most frequently used by the elderly residents for both neighborhoods are bedrooms. Whether in the case of small or large house, bedroom is becoming the room that is frequently used. This can be understood since the elderly in common sense is known as an individual with declination of physical capability. They are assumed to be less mobile than younger person. Concerning this, when they spend much of their daily time in their room, the quality of the room should receive more considerations in order to support their aging life.

A study on one aging neighborhood in South Australia (Karuppannan \& Sivam, 2013) mentioned that if the built environment is not friendly enough for the aging people, then these senior residents will be mainly restrained to their homes, they will get more problems of depression, isolation and even physical illness. According to (Altman \& Et.al, 1984), in the life of persons, determined parts of their environment have larger functional relevance than others. The home environment properties more tend to have a potential of giving impact the inhabitants' environmental experiences than the properties of the environment outside the activity range.

Poor conditions of lighting and ventilation found in elderly spaces in both neighborhoods lead to the finding that actually the elderly residents' live in the high densely settlement at the urban area is vulnerable even in their own home environment. Although some of the respondents mentioned that they got used to such poor conditions, the facts indicate that their health is really threatened.

\section{CONCLUSION}

This study concludes that in urban settlement with high density and aging population, the subtle vulnerability of the senior residents actually exists. This vulnerability is sourced at the conditions of natural lighting and fresh air ventilation that are performed by the home environment properties. Other finding shows that in the case of neighborhoods in the mid of high densely urban settlement, house size is not significantly associated with the quality of lighting and ventilation condition. Getting familiar for a long time with poor lighting as well poor ventilation potentially pursue a gradual decay to the elderly's condition, both in physical and mental health. Based on this summary, such technical intervention to the existing home environment and the advocacy by the design facilitator should be carried out. The result of this study would be useful to provide better understanding on the factual situation attached to the elderly residents who live in the middle of the high densely settlement in the city center. Further discussion on the result would constitute a challenging finding in order to reduce the possibility of poor conditions in the future.

\section{REFERENCES}

Altman, I., \& Et.al. (1984). Elderly People and the Environment, Human Behavior and Environment. Springer Science + Business Media LLC, 7, 261.

Burton, E., Michell, L., Stride, C. (2011). Good places for ageing in place: development of objective built environment measures for investigating links with older people's wellbeing. BMC Public Health, 11, 839-852.

Elo, S. (2010). The physical, social and symbolic environment supporting the well-being of home-dwelling elderly people. International Journal of Circumpolar Health, 70(1), 90-100.

Feddersen, E., \& Ludtke, I. (2009). A Design Manual: Living for the Elderly. Birkhauser.

Galof, K., \& Gricar, N. (2017). Independent Living of the Elderly in the Home Environment. International Journal of Health Sciences June, 5(2), 11-16.

Hauge, S., \& Kristin, H. (2008). The Nursing home as a home: a field study of residents' daily life 
in the common living rooms,. Journal of Clinical Nursing, 17(4), 460-467.

Isaac, G., \& Et.al. (1975). Housing for The Elderly: the development and design process. NY: Van Nostrand Reinhold Company.

Iwarsson, S. et. a. (2007). Importance of the Home Environment for Healthy Aging: Conceptual and Methodological Background of the European ENABLE-AGE Project. The Gerontologist, 47(1), 78-84.

J, W. (n.d.). Aging in place: universal design is in demand. Smarter buildings. In 2125 (hal. 2004). Diambil dari http://www.buildings.com/articledetails/articleid

Karuppannan, S., \& Sivam, A. (2013). Healthy Ageing and Neighbourhood Design: A Case Study in South Australia. International of Aging Society, 2(1), 39-52.

Keman, S. (2005). Kesehatan Perumahan dan Lingkungan Pemukiman. Jurnal Kesehatan Lingkungan, 2(1), 29-42.

Korosec Serfaty, P. (1984). The Home from Attic to Cellar. Journal of Environmental Psychology, $4(1), 303-321$.

Marcus, C. (1995). The House as A Mirror of Self. Conai Press.

Neufert, E. (1990). Architect's Data. (S. Amri, Ed.). Jakarta: Erlangga.

Parker, R. G. (1999). Reminiscence as Continuity: Comparison of Young and Older Adults. Journal of Clinical Geropsychology, 5(2), 147-157.

Pramitasari, D., \& Et, A. (2014). Social Interaction of Nursing Homes Patients and Its Spatial Implications, Case Studies: two nursing homes in Yogyakarta Indonesia. Journal of Habitat Engineering and Design, 6(1), 27-39.

Pramitasari, D., \& TYW, S. (n.d.). Evaluation on Temporary House for the Merapi's Eruption Victims, Case Studies: Temporary Settlement of Kuwang. In Annual Engineering Seminar 2012 (hal. 16). Faculty of Engineering, UGM, Yogyakarta Indonesia.

Szanton, S. (2014). Improving unsafe environments to support aging independence with limited resources. Nursing Clinic North America, 49(2), 133-145.

Temelova, J. (2012). Residential satisfaction of elderly in the city center: the case of revitalizing neighborhoods in Prague. Cities, 29(5), 310-317.

.(2011). Housing Density and Health: A review of the literature and health impact assessments. UNSW Research Centre for Primary Health Care and Equity;p. 16. 